\title{
Potential Treatment of Psoriasis with Oral Spironolactone as TNF-Alpha Inhibitor - A Future Prospective Review
}

\author{
Dr. Sanjana Mehta ${ }^{1}$, Dr. Parminder Nain ${ }^{2}$, Dr. Jaspreet Kaur ${ }^{3 *}$ \\ ${ }^{1}$ Research Scholar, Maharishi Markandeshwar College of Pharmacy, Maharishi \\ Markandeshwar (Deemed to be University), Mullana. \\ ${ }^{2}$ Professor and Head, Maharishi Markandeshwar College of Pharmacy, Maharishi \\ Markandeshwar (Deemed to be University), Mullana. \\ ${ }^{3}$ Associate Professor, Maharishi Markandeshwar College of Pharmacy, Maharishi \\ Markandeshwar (Deemed to be University), Mullana. \\ 1'dr.sanjanamehta@gmail.com, ${ }^{2}$ parminder.nain26@gmail.com, ${ }^{3 *}$ preetisidana@gmail.com
}




\begin{abstract}
:
Psoriasis is a chronic dermatological condition that cause scaly red patches on the different parts of body. It always tends in cycles of months wherein winter aggravation is most common then it subsides for a while then again relapse or remission. The exact identity of the factors causing psoriasis is not established but the fact that T cell activates the release of proinflammatory cytokines such as TNF- $\alpha$, interferon- $\gamma$ and IL-2 has been identified. Cytokine, TNF- $\alpha$ plays a key role in keratinocyte proliferation and other vascular changes in psoriasis. TNF- $\alpha$ protein levels has been found on higher side in psoriasis lesions, intraepidermal Langerhans cells and dermal dendrocytes. The available treatment options for suppressing TNF- $\alpha$ are given only by IV/SC route like adalimumab, infliximab and etanercept also costlier and give only symptomatic relief for a shorter period of time. Hence, we need a pharmacologically active, therapeutically safe and cost-effective agent for long term use. Against all the available data, Spironolactone an aldosterone antagonist has been found to fulfill all the necessary conditions to be used as TNF- $\alpha$ antagonist, a noticeable suppressive effect on TNF- $\alpha$ receptor along with several pro-inflammatory cytokines. Such findings encouraged beginning of clinical studies of spironolactone as TNF- $\alpha$ antagonist in patients with psoriasis.
\end{abstract}

Key words- Psoriasis, TNF- alpha, Spironolactone, pro-inflammatory cytokines

\title{
1. Introduction:
}

Psoriasis is a noncontiguous chronic inflammatory disease of skin, affecting $2 \%$ of the world population

${ }^{[1,2]}$. It is characterized by complex alterations in epidermal growth by abnormal proliferation of keratinocytes, multiple inflammatory cell infiltration and increased vascular abnormalities ${ }^{[3,4]}$. It is an immune-mediated skin disease influenced by genetic and epigenetic variations, which can be triggered by environmental factors ${ }^{[5,6]}$.

Generally, psoriasis begins to appear in men and women equally between the ages of $20-70$ years ${ }^{[7,8]}$. In Psoriasis recurrent episodes of red and scaly skin plaques that are sharply demarcated from adjacent normal skin. The major clinical manifestations of psoriasis include characteristic cutaneous lesions, erythematous papules or guttate and/or pustular lesions topped by whitish silvery scales. The papules combine to form plaques of different shapes and patterns, especially on the scalp, groin, nails, elbows and knees Whereas, the percentage of body being affected with scales varies from person to person ${ }^{[6,9]}$. The psychological and physical stress of psoriasis is equivalent to the patients of cancer, diabetes, heart disease or depression as it affects individual's daily life on many levels including personal, social and professional life ${ }^{[1,10]}$.

Based on the age of onset of symptoms, course of disease, type of skin lesions and location, several clinical classifications of psoriasis are made like plaque psoriasis, psoriasis guttate, scalp psoriasis, pustular psoriasis, psoriasis erythroderma, and inverse psoriasis as shown in table-1 but plaque psoriasis of psoriasis vulgaris accounts for $85-90 \%$ of all cases ${ }^{[1,4,9]}$. 
Table 1. Classification of Psoriasis According to World Health Organization

\begin{tabular}{|c|c|c|}
\hline Types of Psoriasis & Morphological Appearance & Characteristics \\
\hline Plaque Psoriasis & & $\begin{array}{l}\text { - The most common type of psoriasis, } \\
\text { affects between } 58 \% \text { (79) and } 97 \% \text { (45) } \\
\text { of all patients. } \\
\text { - Inflammatory red, sharply demarcated, } \\
\text { raised, dry } \\
\text { Differently sized plaques, usually covered } \\
\text { by silvery or white scales. } \\
\text { - Involves the scalp and the area behind the } \\
\text { ears, } \\
\text { - the extensor surfaces of the forearms and } \\
\text { shins (especially elbows and knees), } \\
\text { trunk, face, palms, soles and nails. }\end{array}$ \\
\hline Psoriasis Guttate & & $\begin{array}{l}\text { - Affects between } 0.6 \% \text { (45) and } 20 \% \text { (8) } \\
\text { of } \\
\text { - } \text { individuals diagnosed with psoriasis and } \\
\text { usually } \\
\text { - occurs in childhood and adolescence. } \\
\text { - Reddish, drop-like papules and plaques, } \\
\text { mainly } \\
\text { - involving the trunk, arms and legs. } \\
\text { - Onset is associated with streptococcal } \\
\text { infection of the upper respiratory tract } \\
\text { and prior skin symptoms }\end{array}$ \\
\hline Pustular Psoriasis & & $\begin{array}{l}\text { - Affects between } 1.1 \% \text { (45) and } 12 \% \\
\text { - } 105) \text { of all cases of psoriasis. } \\
\text { Coalescing pustules, filled with non- } \\
\text { infectious pus. } \\
\text { - Involves either small areas such as palms } \\
\text { of the } \\
\text { - hands, fingertips, nails and soles of the } \\
\text { feet, or the } \\
\text { - entire body surface can occur as a single } \\
\text { episode } \\
\text { after a trigger. }\end{array}$ \\
\hline
\end{tabular}




\begin{tabular}{|c|c|}
\hline $\begin{array}{l}\text { Psoriasis } \\
\text { Erythroderma }\end{array}$ & $\begin{array}{l}\text { - Affects between } 0.4 \% \text { (45) and } 7 \% \text { (105) } \\
\text { of all } \\
\text { cases of psoriasis. } \\
\text { - Fiery redness and exfoliation of most of } \\
\text { the body } \\
\text { - surface. } \\
\text { - The most serious type of psoriasis, } \\
\text { potentially life-threatening, } \\
\text { - Because it can lead to hypothermia, } \\
\text { hypoalbuminemia and high output cardiac } \\
\text { failure }\end{array}$ \\
\hline Inverse Psoriasis & $\begin{array}{l}\text { - Affects between } 12 \% \text { (105) and } 26 \% \text { (21) } \\
\text { of all } \\
\text { cases of psoriasis. } \\
\text { - Deep-red or white, flat, sharply } \\
\text { demarcated, wet } \\
\text { patches or plaques, scales are usually } \\
\text { absent. } \\
\text { - Affects almost exclusively flexural body } \\
\text { sites -axillae, antecubital fossae, } \\
\text { inframammary creases, } \\
\text { umbilicus, groins, genital area, gluteal } \\
\text { cleft, popliteal fossae and other body } \\
\text { folds }\end{array}$ \\
\hline
\end{tabular}

\section{Pathophysiology:}

Psoriasis is a persistent inflammatory illness in which $\mathrm{T}$ lymphocytes, dendritic cells, macrophages, keratinocytes and neutrophils are accountable for the initiation of skin irruptions ${ }^{[11]}$. However, the exact mechanism behind psoriasis is not known but it has been found from the literature that most of psoriatic patients contain a huge amount of circulating levels of TNF- $\alpha$ with IFN-gamma \& IL-12 in both blood and lesioned skin ${ }^{[12,13]}$. Also, TNF- $\alpha$ is believed to have a primary role in many inflammatory disorders like-autoimmune diseases, shock syndromes, heart failure or cachexia ${ }^{[14]}$.

TNF- $\alpha$ is extremely pro-inflammatory cytokine that secreted by both Antigen-Presenting Cells (APC's) and $\mathrm{T}$ cells within lesioned skin and it also exaggerates the inflammation through numerous distinct pathways ${ }^{[6,15]}$. Primarily producing the macrophages, then facilitating access of inflammatory cells into lesioned skin through induction of adhesion molecules on vascular endothelial cells with the help of keratinocytes, finally activating dendritic cells and dermal macrophages ${ }^{[6,16]}$. An important role of TNF- $\alpha$ is to maintain the antigen-presenting ability of dendritic cells and stimulation of T-cell infiltration. It has numerous effects because TNF receptors are of two types - TNFR1 and TNFR2. TNFR1 is present on almost all cell types, but TNFR2 is abundantly present on hematopoietic cells and endothelial cells ${ }^{[6,17]}$. TNF- $\alpha$ also plays important roles at cellular and tissue level. At the cellular level- TNF- $\alpha$ has roles in lymphocyte and neutrophil adhesion, stimulation of collagenase and prostaglandin E synthesis, decreased hemopoiesis, also increase the production of other cytokines. At the tissue level it participates in bone resorption, proteoglycan breakdown and acute tubular necrosis as shown in Figure $1^{[18]}$. 


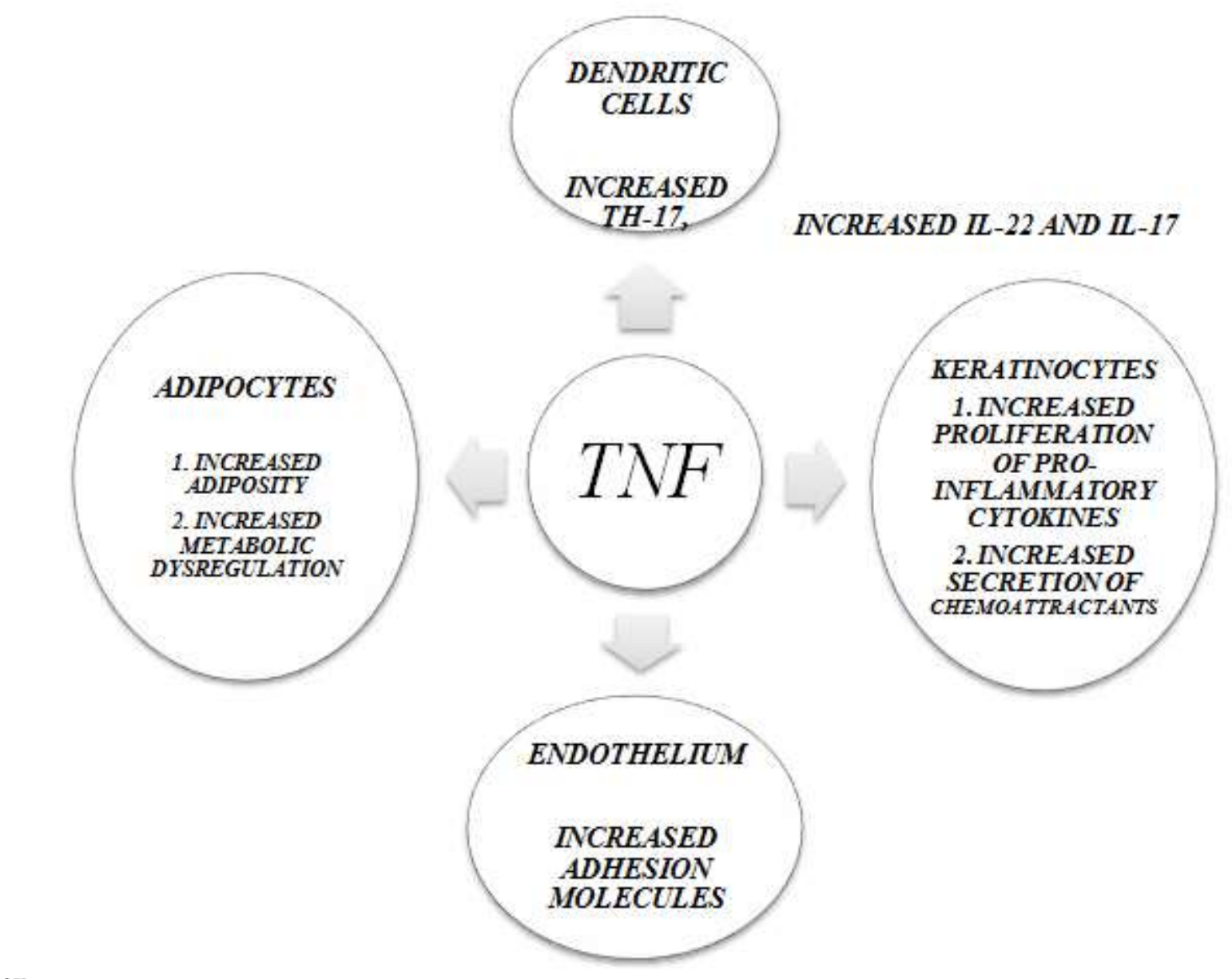

$\mathrm{cx}$

Figure 1. Role of TNF- $\alpha$ in psoriasis

In the pathogenesis of psoriasis, TNF- $\alpha$ elevate the level of active, phosphorylated NF- $\kappa B^{[19]}$. It activates the expression of various cytokines like IL-6 (responsible for induction of T-cell proliferation and hyperproliferation of keratinocyte) and IL-23 the C-reactive protein responsible for acute phase response and is a potential mediator in psoriasis to stimulate IL-17 production from dendritic cells. Several chemokines like CXCL8/IL-8 and CCL20 are also induced by TNF- $\alpha$. Recruitment of neutrophil infiltration and recruitment of myeloid dendritic cells and Th17 cells is done by CXCL8, IL-8and CCL20 respectively. Hence, in psoriasis TNF- $\alpha$ plays a crucial part in regulation of the IL-23/Th17 axis ${ }^{[18-20]}$.

\section{Management of psoriasis with available TNF- $\alpha$ inhibitors:}

Currently, a number of treatments are available to manage psoriasis; however, the available treatment options just give symptomatic relief and are not able to cure the disease. They are mainly focused on suppressing the immune system by steroids either topical or systemic which in turn have side effects and higher rebound or relapse rate when discontinued. The drug of choice in this disease depends on the patient's age, severity of the pathology, general health, the affected body parts and the co-morbidities. Overall, a treatment is based on The Psoriasis Area and Severity Index (PASI) score of the patient ${ }^{[1,22]}$. Then steroids and other agents fail to suppress the disease then besides being the costlier, biological modifier treatment of psoriasis (TNF- $\alpha$ antagonists) are preferred. TNF- $\alpha$-antagonists were initially approved for RA treatment, but years before being permitted for psoriasis treatment. Anti-TNF- $\alpha$ treatment came to existence, to reduce the interactions between keratinocytes and immune cells by 
capturing and blocking the activity of TNF- $\alpha$. There are different effective TNF- $\alpha$ antagonists that down regulates dendritic cells and T-cells along with decreasing other cytokine levels in the treatment of psoriasis. But, at present, only three TNF- $\alpha$ inhibitors (IV/SC) are permitted to be used as anti-psoriatic agents as described in table- 2 .

Table 2. TNF- $\alpha$ Inhibitors for Treatment of Psoriasis

\begin{tabular}{|l|l|l|l|l|}
\hline Drug name & Type of Agent & Efficacy (\% with & Administration \\
PASI 75)
\end{tabular}

Humanized IgG1 monoclonal antibody, Adalimumab binds with high affinity and specificity to human TNF- $\alpha$. It has been suggested to administer it subcutaneously every two weeks for up to 12 weeks of therapy. To inhibit TNF-involved biologic responses, it neutralizes biologic activity by inhibiting its interaction with the p75 and p55 cell-surface ${ }^{[1,6,23]}$. A chimeric monoclonal antibody, Infliximab suppresses TNF- $\alpha$ biological activity by neutralizing both membrane-bound and soluble forms of TNF- $\alpha$. It rapidly normalizes differentiation of keratinocyte, epidermal $\mathrm{T}$-cell infiltration, reduces epidermal thickness, intracellular adhesion of molecules, such as VCAM and e-selectin ${ }^{[1,6,24]}$. A fusion protein, Etanercept is a dimeric form of the soluble TNF p75 receptor consisting of the extracellular ligandbinding area of TNF- $\alpha$ receptors and Fc. It performs its function on immune system by initially neutralizing soluble TNF- $\alpha$ and TNF- $\beta$ then binding them and making them biologically inactive. It is advised to be administered subcutaneously twice per week. This molecule has a higher affinity for TNF- $\alpha$ than the natural receptor. This treatment also helps in reduction of psoriatic inflammation ${ }^{[1,6,25]}$. Certolizumab Pegol is a humanized recombinant, TNF- $\alpha$ antagonist antibody is currently used for Crohn's disease and RA. But it is now under investigation to use in psoriasis (phase II results are available) ${ }^{[6,26]}$.

\subsection{Spironolactone:}

Spironolactone, an aldosterone receptor antagonist according to pharmacologic classification is potassium-sparing diuretic ${ }^{[27-28]}$. As per therapeutic indications it is used in the management of edema, as an antihypertensive, in the treatment of diuretic-induced hypokalemia and has OFF-LABEL use in treating acne in females ${ }^{[29]}$. It works by maintaining the osmotic pressure of the body by eliminating extra sodium and water into the urine, but spares the loss of potassium from the body. It has been studied that spironolactone also play a vital role in pathological conditions. ${ }^{[30]}$ 


\subsection{Effect of spironolactone on production of cytokines (in vitro):}

An in-vitro study shows, spironolactone significantly suppresses (70-90\%) cytokines (TNF- $\alpha$, IFN-g, LTa, IL-6, osteopontin) release and also inhibits its production at genetic level. But the exact mechanism behind the suppressive nature of this drug is not clear as it was unable to control the release of macrophage-derived pro-inflammatory cytokine IL-1b ${ }^{[27-30]}$.

\subsection{Effect of spironolactone therapy on cytokine production in (ex-vivo):}

It was an unknown fact that non-protein-bound, free fraction of the drug is responsible for suppressive effects of Spironolactone on cytokine production. Therefore, to be certain about it, two patients with rheumatoid arthritis were treated for 2 weeks with $50 \mathrm{mg}$ oral spironolactone twice daily and when pre and post treatment leucocytes were compared it came out that patients produced less TNF- $\alpha$, IFN-g, LT$\alpha$, IL-6 and GM-CSF ${ }^{[27]}$ as shown in Table-3.

Table 3. Effect of Spironolactone on Cytokine TNF- $\alpha$ Production

\begin{tabular}{|l|l|l|l|l|l|}
\hline Cytokines levels in (pg/ml) & \multicolumn{2}{l|l|l|}{ Patient 1 } & \multicolumn{2}{l|}{ Patient 2 } & of control mean \\
\hline & Before & After & Before & After & \\
\hline TNF- $\alpha$ & 1110 & 1850 & 130 & 650 & $23 \%$ \\
\hline IFN-g & 4300 & 1140 & 1230 & 700 & $42 \%$ \\
\hline LT- $\alpha$ & 170 & 48 & 270 & 54 & $24 \%$ \\
\hline IL-6 & 22350 & 9700 & 14200 & 4355 & $37 \%$ \\
\hline GM-CSF & 3460 & 2740 & 1090 & 610 & $68 \%$ \\
\hline
\end{tabular}

\subsection{Effect of spironolactone in skin disorders:}

Spironolactone and its metabolite canernone both at the level of nuclear and cytosolic mineralocorticoid receptors act as a competitive aldosterone antagonist. But, in a study it was found that canrenone failed to change the release of the cytokines. This justifies that spironolactone's inhibitory effect on proinflammatory cytokines production is not related to its effect on mineralocorticoid receptors ${ }^{[27,28]}$.

The Journal of Investigative Dermatology had also published an online study, in which the researchers reported a hypothesis that activation of mineral corticoids receptors in the epidermal layer of the skin might be due to corticosteroid-based dermatological ointments. These receptors are found highly sensitive to corticosteroids in previous studies and are also present in the eye, heart and kidney too. In an in vitro study of cultured skin observed that, corticosteroid ointments are causing skin atrophy by one/third. To rectify the side-effect, an antagonist such as spironolactone- a mineralocorticoid receptor blockers was found to be that skin atrophy had significantly reduced by adding spironolactone with corticosteroid. Thus, the researchers provided a concept with proof of efficacy to dermatologists to use topical spironolactone as an adjuvant in patients who need short-term glucocorticoid treatment like psoriasis and eczema, but necessary measures like reformulation of ointment, assessment of toxicology and clinical evaluation in dermatologic patients are yet to be performed ${ }^{[30]}$. 


\section{Conclusion:}

We have observed that in recent years, different classes of drugs have been developed for psoriasis and many drugs are under process but still no drug is available for the cure of this disease's pathology. Now a day, Role of anti-TNF agents as a key component of the treatment in moderate to severe psoriasis have increased but being a costly treatment access to these drugs remains limited. In addition, a lot of serious side effects during treatment period and after completion of the regimen have been observed with the available drugs. The discovery of new immunological factors and an enhanced knowledge on pathology of psoriasis, gives major opportunity to address new drugs such as spironolactone (orally) to cover the health economic, safety and efficacy aspects with fewer side effects than conventional ones. So, there is a wealth of information from both real-life clinical practice and clinical studies have collected to show that spironolactone can be initiated alone or as an adjuvant without any cooperation in efficacy or safety.

\section{Acknowledgements:}

Authors are thankful to the management of M.M. College of Pharmacy, Maharishi Markandeshwar (Deemed to Be) University, India for encouragement and necessary facilities support.

\section{Abbreviations:}

Tumor Necrosis Factor-Alpha: TNF- $\alpha$

Tumor Necrosis Factor Receptors: TNFR

Intravenous/Sub-Cutaneous: IV/SC

Nuclear Factor-Kappa B: NF- $\kappa$ B

Rheumatoid Arthritis: RA

Interleukin: IL

T Helper cells: $\mathrm{TH}$

CXCL: C-C Motif Ligand

CCCL: C-X-C Motif Ligand

\section{References:}

1. S.D. Declercq, R.Pouliot, "Promising New Treatments for Psoriasis", Sci. World J., 2013, 1-9.

2. M.P. Schon, W.H. Boehncke, "Psoriasis", N. Engl. J. Med., 2005, 352(18), 1899-1912.

3. K.E.Nograles,J.G.Krueger, "Anti-cytokine therapies for psoriasis," Exp.Cell Res., 2011,317(9),1293-1300.

4. F.O.Nestle, D.H. Kaplan, J.Barker, "Psoriasis", N. Engl. J. Med., 2009,361(5),496-509.

5. G.K.Perera, P.Dimeglio, F.O.Nestle, "Psoriasis”, Annu Rev Pathol-Mech., 2012, 7, 385-422.

6. R.L. Jirtle, M.K. Skinner, "Environmental epigenomics and disease susceptibility", Nat Rev Genet., $2007,8(4), 253-62$.

7. D.Hagg, A.Sundstrom, M.Eriksson, M.S. Egenolf, "Severity of Psoriasis Differs Between Men and Women: A Study of the Clinical Outcome Measure Psoriasis Area and Severity Index (PASI) in 5438 Swedish Register Patients", Am J Clin Dermatol.,2017,18 (4),583-590.

8. World Health Organization, Global report on psoriasis, 2016.

9. C.E.Griffiths, J.N.Barker, "Pathogenesis and Clinical Features of Psoriasis", Lancet., 2007, 370(9583), 263-271.

10. S.R.Rapp, S.R.Feldman, M.L.Exum, A.B.Jr.Fleischer, D.M. Reboussin, "Psoriasis causes as much disability as other major medical diseases”, Acad. Dermatol JAAD., 1999, 41(3), 401-407. 
11. M.A.Lowes, M.S. Farinas, J.G. Krueger, "Immunology of psoriasis", Annu Rev Immunol., 2014, 32, 227-55.

12. E.H.Herrera-Garza, S.J.Stetson, A.G.Cubillos, M.T.Vooletich, J.A.Farmer, G.A.Torre, "Tumour necrosis factor- $\alpha$ : A mediator of disease progression in the failing human heart" ,CHETBF., 1999,115,1170-1174.

13. K.J. Tracey, H.Vlassara, A.Cerami, "Cachectin/Tumour Necrosis Factor” , Lancet.,1989;1,11221126.

14. P.J. Mease, "Tumour Necrosis Factor (TNF) in Psoriatic Arthritis: Pathophysiology and treatment with TNF inhibitors", Ann Rheum Dis., 2002, 61, 298-304.

15. L.C. Zaba, J.F.Duculan, N.J.Eungdamrong, L.M. Johnson-Huang, K.E. Nograles, T.R. White, et al, "Identification of TNF-related apoptosis-inducing ligand and other molecules that distinguish inflammatory from resident dendritic cells in patients with psoriasis", J. Allergy Clin. Immunol., 2010, 125(6),1261-1268.

16. M.A.Lowes, F.Chamian, M.V.Abello, J. Fuentes-Duculan, S.L. Lin, R. Nussbaum, et al, "Increase in TNF-alpha and inducible nitric oxide synthase-expressing dendritic cells in psoriasis and reduction with Efalizumab (anti-CD11a)", PNAS USA., 2005, 102(52),19057-19062.

17. O. Arican, M. Aral, S. Sasmaz, P. Ciragil, "Serum levels of TNF-alpha, IFN-gamma, IL-6, IL-8, IL12, IL-17, and IL-18 in patients with active psoriasis and correlation with disease severity", Mediators Inflamm., 2005,5,273-279.

18. A.Abanmi, Al.Harthi, R.Al.Agla, H.A. Khan, M.Tariq, "Serum levels of proinflammatory cytokines in psoriasis patients from Saudi Arabia”, Int. J. Dermatol., 2005; 44(1),82-83.

19. A.M.Goldminz, S.C.Au, N.Kim, A.B. Gottlieb, P.F.Lizzul, "NF-kappaB: An essential transcription factor in psoriasis", J Dermatol Sci., 2013, 69(2), 89-94.

20. S.E. Jacob, M.Nassiri, F.A.Kerdel, V.Vincek, "Simultaneous measurement of multiple Th1 and Th2 serum cytokines in psoriasis and correlation with disease severity", Mediators Inflamm., 2003,12(5), 309-313.

21. J.Yost, J.E.Gudjonsson, "The role of TNF inhibitors in psoriasis therapy: new implications for associated Comorbidities", F1000 Med Rep., 2009,1,30.

22. U.Mrowietz, K.Kragballe, K.Reich, P.Spuls, C.E. Griffiths, A.Nast, et al, "Definition of treatment goals for moderate to severe psoriasis: A European consensus", Arch Dermatol Res., 2011, 303(1), $1-10$.

23. A. Menter, S.K.Tyring, K.Gordon, A.B. Kimball, C.L.Leonardi, R.G.Langley, et al, "Adalimumab therapy for moderate to severe psoriasis: A randomized, controlled Phase-III trial”, Acad. Dermatol JAAD., 2008, 58(1),106-115.

24. K.Reich, F.O.Nestle, K.Papp, J.P.Ortonne, R.Evans, C.Guzzo, et al, "Infliximab induction and maintenance therapy for moderate-to-severe psoriasis: A phase III, Multicentre, double-blind trial", Lancet., 2005,366(9494), 367-1374.

25. K.A. Papp, S.Tyring, M.Lahfa, J.Prinz, C.E. Griffiths, A.M.Nakanishi, et al, "A global phase III randomized controlled trial of etanercept in psoriasis: safety, efficacy, and effect of dose reduction" Br. J. Dermatol., 2005,152(6),1304-1312.

26. K.Reich, A.D. Burden, J.N. Eaton, N.S. Hawkins, "Efficacy of biologics in the treatment of moderate to severe psoriasis: a network meta-analysis of randomized controlled trials", Br. J. Dermatol., 2012, 166(1), 179-188.

27. K.Bendtzen, P.R. Hansen, K. Rieneck, "The Spironolactone/Arthritis Study Group, Spironolactone inhibits production of proinflammatory cytokines, including Tumour Necrosis Factor-alpha and interferon G, and has potential in the treatment of arthritis", Clin Exp Immunol., 2003,134,151-158.

28. R.Sorrentino, G.Autore, G.Cirino, R.V. Bianca, A.Calignano, M.Vanasia, et al, "Effect of spironolactone and its metabolites on contractile property of isolated rat aorta rings" ,J Cardiovasc Pharmacol.,2000,36,230-235.

29. G.S. Blair, N.D. Allie, "Spironolactone use for women with acne or hirsutism”, JDNA.,2011.3. 
30. B.Pitt, F.Zannad, W.J. Remme, R.Cody, A. Castaigne, A. Perez et al, "The effect of spironolactone on morbidity and mortality in patients with severe heart failure-Randomized Aldactone Evaluation Study Investigators", N Engl J Med., 1999,341,709-717. 